\title{
UM ÍNDICE DE MÍNIMA VARIÂNCIA DE AÇÕES BRASILEIRAS
}

\author{
César Thomé Neto * \\ Ricardo Pereira Câmara Leal ${ }^{\dagger}$ \\ Vinício de Souza e Almeida $\ddagger$
}

\begin{abstract}
Resumo
Este trabalho desenvolve um índice de carteiras de mínima variância global (MVP) para as ações mais líquidas do Brasil. Os resultados indicaram que a MVP sem limites sobre os pesos das ações não apresenta diferença significativa de desempenho em relação ao IBOVESPA. A imposição de um peso máximo de dez por cento em cada ação tornou possível superar o IBOVESPA. Contudo, os resultados desta estratégia são comparáveis aos de uma carteira igualmente ponderada e são superados por alguns fundos de gestão ativa em testes fora da amostra. Ainda assim, estas estratégias simples baseadas nestas restrições facilitam a replicação do MVP por investidores individuais e exchange traded funds e sustenta o poder de estratégias ingênuas de investimento.
\end{abstract}

Palavras-chave: Carteira de Mínima Variância; Desempenho de Fundos; Seleção de Ativos.

\begin{abstract}
This paper develops an index of global minimum variance portfolio (MVP) for the most liquid stocks in Brazil. The unconstrained MVP shows no significant difference in performance over the IBOVESPA. The imposition of a ten percent ceiling on the MVP weights for each asset made it possible to beat the IBOVESPA. However, this strategy is comparable to an equally weighed portfolio and is beaten by a number of actively managed stock funds in out of the sample tests. Nevertheless, these constraints facilitate the replication of the MVP by individual investors and by ETFs and support the power of naive diversification strategies.
\end{abstract}

Keywords: Minimum Variance Portfolio; Fund Performance; Portfolio Selection.

JEL classification: G11

\footnotetext{
*Foz do Brasil, cesar.thome@yahoo.com

† Coppead/UFRJ, rleal@ufrj.br

‡ PPGA/UFRN, almeida.vinicio@gmail.com
} 


\section{Introdução}

Investir em ações pode oferecer alto potencial de retorno, porém com risco elevado. Tversky \& Kahneman (1991) admitem que a possibilidade de perdas influi nas preferências dos indivíduos mais do que o potencial de ganhos. Kahneman \& Tversky (1979) também afirmam que as pessoas dão mais peso aos resultados certos do que aos resultados prováveis. Clarke et al. (2006) e Ang et al. (2006) concluíram que os ativos com mais volatilidade histórica ofereceram retornos menores do que os menos voláteis. A aversão à perda dos investidores e os resultados ruins de investimentos de alta volatilidade certamente afasta muitos deles do mercado de ações. É possível que o investimento em ações por meio de um veículo que ofereça a menor volatilidade possível e que seja fácil de compreender seja bem aceito pelos investidores mais reticentes.

O Fundo de Investimento em Ações (FIA) é um veículo muito comum para se investir em ações. Um fundo de ações pode balizar seu desempenho segundo um dos índices de ações mais comuns do país, como o IBOVESPA ou o IBrX $X^{1}$.Contudo, não há qualquer garantia que a carteira destes índices seja uma carteira eficiente no sentido de Markowitz (1952), isto é, uma carteira que ofereça o maior retorno esperado possível para seu nível de risco, medido pelo desvio-padrão dos retornos históricos das ações. A carteira de um índice pode ser formada segundo critérios de liquidez ou de valor de mercado das companhias e pode ser limitada a um número arbitrário de empresas. É possível, portanto, que haja uma carteira com o mesmo risco da carteira teórica do índice que ofereça maior retorno e que seja eficiente, pelo menos em relação ao conjunto de ações considerado.

A proposta deste trabalho é verificar se uma carteira eficiente, em relação a uma amostra limitada de ações, pode ser uma referência de desempenho superior aos índices tradicionais. Considerando o possível apetite dos investidores por veículos para investimento em ações com a menor volatilidade possível, a carteira eficiente que é candidata natural para análise é a de menor variância na fronteira eficiente. Essa carteira foi chamada na literatura internacional de global minimum variance portfolio (MVP), ou carteira de mínima variância global, como em Constantinides \& Malliaris (1995), por exemplo. Uma MVP pode servir tanto de referência de desempenho para gestores de fundos, na forma de um novo índice de ações, quanto se pode criar produtos a serem oferecidos aos investidores baseados nesta carteira, como um exchange traded fund (ETF), um fundo que negocia como uma ação em bolsa, tal como o bem conhecido PIBB (Papéis de Índice Brasil Bovespa), que busca resultados semelhantes ao desempenho do IBrX-50, similar ao IBrX, mas com somente 50 ações.

A análise realizada investigou se MVPs formadas segundo vários critérios simples apresentaram desempenho superior, relativo ao risco, ao do indicador mais usado no mercado nacional, o IBOVESPA. As MVPs também foram comparadas a fundos de ações de gestão ativa e a uma carteira igualmente ponderada de ações. Os resultados sugerem que as MVP têm grande potencial para servir de base para índices de mercado, estratégias de investimento

\footnotetext{
${ }^{1}$ Respectivamente, Índice Bovespa, composto por cerca de 70 ações selecionadas e ponderadas a cada quadrimestre segundo sua liquidez, e Índice Brasil, composto por 100 ações selecionadas segundo sua liquidez e ponderadas pela quantidade de ações disponível para negociação.
} 
e produtos, como os ETF, e que as regras comumente empregadas pelos profissionais de mercado, como a limitação tanto do valor dos pesos dos ativos nas carteiras quanto da amostra de ações a serem consideradas, têm grande mérito.

\section{Antecedentes na Literatura}

A construção de um índice que emprega a metodologia de Markowitz (1952) encontra respaldo na literatura. Constantinides \& Malliaris (1995) afirmam que Markowitz (1952) conseguiu desenvolver uma metodologia racional para seleção de carteiras sob incerteza porque seu método vai além de reduzir o risco, já que preconiza a busca por ativos que apresentem relações de baixa covariância. Michaud (1989) admite que a teoria de seleção de carteiras por média-variância é um meio de racionalizar o valor da diversificação e apresenta muitos benefícios para os investidores. Entre eles, está um maior controle do risco da carteira pela inserção de restrições concebidas pelos investidores na programação matemática do cálculo dos pesos dos ativos na carteira. O autor também ressalta que o modelo é flexível porque permite que quaisquer expectativas de retornos sejam consideradas e que é possível analisar rapidamente grande quantidade de dados em pouco tempo. Clarke et al. (2006) destacam que essas análises podem ser feitas por meio de cálculo matricial, sem necessidade de usar simulação de Monte Carlo, reduzindo e simplificando o esforço computacional necessário.

A carteira de mínima variância global (MVP) possui características impares dentre as carteiras da fronteira eficiente. Clarke et al. (2006) afirmam que sua principal vantagem e não depender de estimativas de retornos futuros. A carteira e determinada exclusivamente em função da matriz de covariâncias entre os ativos e, por isso, e menos subjetiva do que as demais carteiras na fronteira eficiente. A equação 1 apresenta a forma de se obter os pesos dos ativos da MVP e foi obtida de Constantinides \& Malliaris (1995). $\mathbf{W}_{\mathrm{G}}$ e o vetor de pesos da MVP, $\Sigma^{-1}$ e a matriz amostral de variâncias e covariâncias, 1 é um vetor coluna unitário e $\mathbf{1}^{\top}$ seu transposto. Não ha a necessidade de se ter estimativas para o retorno esperado de cada ativo. Naturalmente, e preciso empregar a media histórica amostral para se calcular as variâncias e covariâncias, mas isto não implica que estes valores são os retornos esperados pelo investidor.

$$
\mathbf{W}_{\mathbf{G}}=\frac{\Sigma^{-1} 1}{1^{T} \Sigma^{-1} 1}
$$

A MVP também se destaca por ser independente da função utilidade do investidor, que é diferente para cada indivíduo. DeMiguel et al. (2009) destacam que a MVP se enquadra na estrutura geral da utilidade esperada de médiavariância quando se supõe que todos os retornos esperados em todos os estados da natureza são iguais.

De fato, Jobson \& Korkie (1981) empregam uma propriedade da estatística matemática derivada por W. James e C. Stein cuja aplicação ao problema de otimização de Markowitz é bastante simples. O estimador de James-Stein é a média das médias históricas dos retornos de cada ação, usado quando não se pode afirmar que o retorno esperado de uma ação é realmente diferente do que o retorno esperado de outra ação qualquer. Jobson \& Korkie (1981) afir- 
mam que, quando isso ocorre, a carteira ótima é a MVP e os retornos esperados são reduzidos (encolhidos, shrinked) a um único número, a média das médias. Disatnik \& Benninga (2007) concluem que os resultados obtidos com métodos mais simples de shrinkage, como o uso da MVP amostral sugerido por Jobson \& Korkie (1981), não se distinguem de métodos mais complexos. Ledoit \& Wolf (2004) empregam o modelo de correlação constante para sua versão de shrinkage em que a matriz de covariâncias amostral é combinada em certa proporção com uma matriz de covariâncias estimada empregando a correlação média de todas as correlações para calcular as novas covariâncias. Eles também apresentam algoritmos para determinar a constante de proporção para a combinação das duas matrizes e concluem que seu método apresenta vantagens claras sob métodos mais complexos de shrinkage e sobre o método clássico de Markowitz (1952). Ledoit \& Wolf (2004) também concluem que quanto menor o número de ativos no problema de otimização, melhor o desempenho do método de shrinkage. Mendes \& Leal (2005) apresentam sua proposta de shrinkage visando dar mais robustez à matriz de covariâncias e afirmam que seu método apresenta vantagens sobre a otimização clássica de Markowitz (1952) ao comparar as carteiras MVP clássica e robusta. Almeida (2012) analisou diversas metodologias para definir o modelo mais adequado ao mercado brasileiro. Em seu estudo, o autor corrobora que o método de shrinkage é capaz de proporcionar melhores estimativas de covariância para ativos negociados no Brasil.

Gohout \& Specht (2007) demonstram que carteiras formadas a partir de premissas racionais, que levam em consideração as relações entre os ativos, tendem a superar os índices usuais de mercado uma vez que estes não são necessariamente carteiras eficientes. Os autores concluem que a carteira formada de acordo com as diretrizes de Markowitz (1952) superou o índice alemão DAX no período analisado. A MVP é, teoricamente, a carteira que oferece o menor risco para o investidor.

O número de ativos a ser manejado também é um fator importante, particularmente para o investidor individual ou para um fundo de investimentos pequeno ou de objetivo restrito ou, ainda, um clube de investimentos. Bloomfield et al. (1977) e Oliveira \& De Paula (2008) afirmam que os custos de manutenção e gestão de uma carteira estão diretamente relacionados à quantidade de ativos da carteira, ao tamanho da amostra de ativos analisados pelo gestor e à sua frequência de atualização. Limitar o número de ativos e seus pesos na carteira pode ser um dispositivo eficaz para reduzir o custo de gestão. DeMiguel et al. (2009) apresentam evidências que favorecem as práticas de arbitrar limites aos pesos dos ativos na carteira e de restringir o número de ativos considerados.

Apesar dos benefícios aparentes, Michaud (1989) afirma que o modelo de média variância é pouco aplicado na prática. O autor acredita que os investidores estão acostumados a tomar decisões informais e alerta que o motivo principal para que as instituições não o empreguem reside em problemas políticos internos. O uso dessa metodologia reduz o poder dos gestores e dos investidores mais seniores, além de demandar mudanças na estrutura da organização, principalmente nos setores de contabilidade e de controle de risco. Michaud (1989) reúne os motivos para a baixa aceitação do modelo entre os investidores em dois grupos. O primeiro é fruto da percepção dos investidores de que o benefício real proporcionado pelo método não justificaria o esforço necessário para implementá-lo. O segundo é a resistência à mudança 
por parte dos investidores.

Green \& Hollifield (1992) ressaltam que as participações dos ativos individuais calculadas pelo modelo de média-variância não se aproximam de zero à medida que o número de ativos disponíveis aumenta. Alguns ativos permanecem na carteira com pesos que podem ser considerados excessivos. Black \& Litterman (1991) afirmam que a inconsistência entre os pesos intuídos pelos investidores em uma diversificação adequada e os pesos resultantes dos modelos de alocação de ativos calculados pelo método de média-variância é uma das maiores barreiras para sua implementação. Green \& Hollifield (1992) afirmam que os praticantes suspeitam das alocações resultantes da aplicação do modelo de média-variância e o implementam juntamente com diversas restrições quanto aos pesos.

Michaud (1989), Best \& Grauer (1991) e Mendes \& Leal (2005), entre outros, afirmam que pequenas mudanças nos dados de entrada para o cálculo dos retornos médios e da matriz de covariância podem causar mudanças significativas nos pesos dos ativos nas carteiras da fronteira eficiente. O modelo do Markowitz (1952) pressupõe que a covariância entre os ativos permanecerá estável. Clarke et al. (2006) confirmam que os ativos possuem variância e covariância relativamente estáveis e, por isso, razoavelmente previsíveis. No entanto, Bauer et al. (2004) duvidam do êxito das técnicas tradicionais de formação de carteiras em momentos de crise e instabilidade do mercado. Os autores afirmam que, nestas situações, a volatilidade e as correlações tendem a aumentar e, portanto, propõem que se recalcule a ponderação das carteiras com a metodologia de média-variância sempre que o mercado apresentar indícios de crise. Todavia, os autores reconhecem que a estratégia sugerida não apresentou vantagens significativas ao final de seu estudo. Leal \& Mendes (2010) realizam um ajuste na matriz de covariâncias empregando uma medida de correlação ajustada pela dependência nas caudas das distribuições obtida por meio de cópulas. Seus resultados indicam que o método obtém melhores resultados que o método clássico de Markowitz apenas em alguns casos, quando a dependência de cauda é fraca ou moderada e não quando é grande, como acontece nas crises.

Michaud (1998) apresentou uma alternativa para o modelo de Markowitz (1952) por meio de reamostragem com a técnica de bootstrapping, em que diversas fronteiras eficientes são obtidas por meio de simulação e os pesos das carteiras para níveis selecionados de risco são obtidos dentro dos intervalos de confiança derivados da distribuição de pesos simulada. No entanto, há várias contestações ao método de Michaud (1998). Fletcher \& Hillier (2001) afirmam que o desempenho de carteiras com pesos calculados pelo método de Michaud (1998) não é superior ao método clássico de Markowitz (1952). Handa \& Tiwari (2006) asseveram que a incorporação da incerteza nos parâmetros de entrada por meio de métodos Bayesianos não melhora o desempenho das carteiras. Mendes \& Leal (2010) criam um método de bootstrapping semi-paramétrico que se sai melhor do que o método proposto por Michaud (1998) em simulações. Harvey et al. (2008) empregam métodos Bayesianos em simulações de alocações de carteiras e concluem que eles superam os métodos baseados em reamostragem propostos por Michaud (1998).

Samuelson (1970), Rubinstein (1973) e Arditti \& Levy (1975) defendem que momentos de ordem superior não podem ser desconsiderados. Harvey et al. (2010) acomodam momentos de ordem superior e métodos Bayesianos em sua análise e afirmam que obtêm resultados superiores aos procedimentos 
de reamostragem uma vez que o procedimento de Michaud (1998) sempre acaba selecionando uma carteira sub-ótima .

DeMiguel et al. (2009) apresentam uma evidência devastadora para todos os modelos de alocação de carteiras, inclusive o original de Markowitz (1952). Eles testam 14 modelos diferentes em simulações fora da amostra e concluem que nenhum deles supera a diversificação ingênua feita com proporções de investimento igual em cada ativo $(1 / N)$. Eles também afirmam que seria necessária uma janela de estimação de 250 anos para que os modelos de médiavariância e seus aprimoramentos superassem a estratégia $1 / \mathrm{N}$ quando se consideram 25 ações na carteira. O tamanho da janela passa para 500 anos com 50 ativos. Os resultados de DeMiguel et al. (2009), no mínimo, favorecem a visão muito comum entre os profissionais de mercado de imposição de limites para a participação dos ativos na carteira e para o total de ativos a ser analisado, além de restrições à venda a descoberto. Os modelos sujeitos a restrições apresentam resultados melhores com dados reais do que os sem restrições.

A conclusão desta revisão da literatura é que há méritos no emprego de carteiras que procuram níveis mais baixos de risco, como a MVP, assim como para restrições quanto ao número de ativos considerado e à proporção de cada ativo na carteira. A restrição a vendas a descoberto também parece ser sustentada pela evidência empírica e pode ser que o emprego de métodos robustos de estimativa da matriz de covariância apresentem vantagens sobre a estimativa clássica da MVP. Contudo, é possível que uma simples carteira com ponderação $1 / N$ também se apresente como um bom indicador de desempenho.

\section{Amostra e método}

Os valores de fechamento diários do IBOVESPA, as cotações diárias médias e de fechamento das ações, com ajuste de proventos e dividendos no período de janeiro de 1998 até dezembro de 2008 foram obtidos da Economática ${ }^{\circledR}$. A base de notícias Bloomberg ${ }^{\circledR}$ forneceu as informações necessárias sobre as mudanças de códigos, fusões e cancelamentos dos ativos ao longo do período estudado. A composição das carteiras teóricas do IBOVESPA, que são alteradas a cada quadrimestre, foram obtidas no web site da BM\&FBovespa e por meio de mensagem enviada diretamente ao suporte da instituição. As ações consideradas na análise são as das empresas que faziam parte do IBOVESPA e variam a cada quadrimestre segundo a regra de revisão de sua carteira teórica. Uma relação das ações que foram analisadas a cada quadrimestre encontra-se disponível com os autores. A base de dados Quantum Axis ${ }^{\circledR}$ forneceu o valor das cotas líquidas diárias dos fundos de investimento empregados na comparação com os índices de mínima variância. A escolha das ações mais líquidas é coerente com o objetivo do trabalho de obter um índice de mínima variância global que seja facilmente replicável e que sirva de alternativa de referência de desempenho aos índices de ações tradicionais. Essa escolha também é sustentada pela evidência recolhida na revisão da literatura de que se deve limitar a amostra de ações analisadas para que os resultados dos modelos de otimização de média-variância sejam melhores.

Algumas empresas fecharam seu capital e outras foram objeto de fusões e de aquisições no período analisado. As cotações de algumas ações que deixaram de negociar durante o período de estudo e que permaneceram na base de dados foram usadas até o último dia em que seus preços foram registra- 
dos para reduzir o viés de sobrevivência. No entanto, em diversos casos, o banco de dados Economática ${ }^{\circledR}$ não mantém as cotações anteriores a essas modificações e, por isso, nesses casos, o estudo considerará somente as ações que não sofreram alterações ou aqueles que somente mudaram o código do ativo negociado. Essa restrição reduz a quantidade de ativos disponíveis e, consequentemente, o número de combinações possíveis para a carteira de mínima variância. Foram excluídas, também, as ações que não negociaram em pelo menos um dia durante o quadrimestre. Houve 192 exclusões de 75 ativos diferentes durante o período de análise, sendo que os períodos com mais exclusões foram os mais distantes, como esperado. A partir do segundo quadrimestre de 1998, o primeiro período considerado, até o terceiro quadrimestre de 1999, foram excluídas, respectivamente, 32, 30, 24, 17 e 20 empresas. Uma lista detalhada das empresas excluídas está disponível com os autores.

As MVP foram construídas com as cotações diárias de fechamento de cada quadrimestre. Os pesos da primeira carteira foram obtidos com base nos preços do primeiro quadrimestre de 1998 para as ações da carteira teórica do IBOVESPA, menos as exclusões, e vigoraram no segundo quadrimestre deste ano. A otimização de média-variância realizada não admitiu vendas a descoberto, para manter a compatibilidade com os índices tradicionais de ações e a facilidade de replicação, e não considerou momentos de ordem superior. Os limites máximos de participação de um ativo na MVP foram de 10, 25, 50 e 75 por cento, além de uma carteira MVP sem este limite. Esses limites reduzirão a variabilidade dos pesos das ações quando do seu cálculo quadrimestral.

A MVP é composta por ações que são mantidas durante os quatro meses seguintes a cada ponderação. A quantidade teórica das ações na carteira não se altera, mas os pesos variam por influência dos preços de mercado. $\mathrm{O}$ peso obtido na otimização é empregado para calcular a quantidade teórica da ação na MVP, como é explicado mais adiante. Manter a quantidade teórica constante durante o período de análise do desempenho da carteira equivale a não rebalancear a carteira diariamente. O uso de cotações diárias já ajustadas para proventos e dividendos tornou desnecessário o rebalanceamento das quantidades teóricas nas datas destes eventos, mas equivale a este rebalanceamento. Este método foi adotado para que as MVPs analisadas equivalessem aos índices tradicionais, que mantém suas quantidades teóricas constantes durante os períodos entre as mudanças de suas carteiras, e as ajustam para dividendos e proventos.

Uma vez obtida uma MVP, seu desempenho será aferido no quadrimestre subsequente. A cotação do dia anterior de uma ação será repetida quando ela não for negociada no período de teste, indicando retorno nulo naquele dia. A MVP será rebalanceada dividindo-se o peso de uma ação que deixe de negociar permanentemente entre as ações que permaneçam na carteira. Este procedimento fará com que as ações com o peso máximo permitido ultrapassem o limite até que haja nova ponderação.

A matriz de covariâncias foi estimada na forma clássica com os retornos históricos do quadrimestre anterior e, alternativamente, por um método robusto. Ledoit \& Wolf (2004) acreditam que a metodologia clássica de cálculo da matriz de covariância apresenta vantagens, como o baixo esforço computacional e a ausência de viés, e como principal desvantagem o erro de estimação elevado. Eles também alertam que o uso exclusivo de estimadores mais estruturados reduz o erro da estimativa, mas introduzem vieses, e concluem que os modelos híbridos, combinando a matriz de covariância e um estimador es- 
truturado são capazes de proporcionar resultados melhores. Mendes \& Leal (2005) adotam essa estratégia empregando duas matrizes de covariância que são ponderadas para formar uma matriz robusta que não seja muito distorcida pelos valores extremos da amostra. Estes autores adotam o estimador Minimum Covariance Determinant (MCD) de Rousseeuw (1984) juntamente com uma variação da matriz de covariância histórica. As MVPs foram calculadas tanto na forma clássica de Markowitz (1952) quanto na forma sugerida por Mendes \& Leal (2005) com base no estimador MCD com o auxílio do algoritmo FAST-MCD desenvolvido por Rousseeuw \& Van Driessen (1999). A rotina computacional para MATLAB foi obtida no web site do Departamento de Estatística Robusta da Katholieke Universiteit Leuven ${ }^{2}$ (Universidade Católica da Lovaina). O ponto de ruptura de 75 por cento e os demais parâmetros usados seguiram as recomendações de Rousseeuw \& Van Driessen (1999).

A equação 2 descreve como foram obtidas as quantidades teóricas que serviriam de base para o cálculo do desempenho do índice MVP durante um quadrimestre. Todas as MVP são índices que iniciam com 100 mil pontos. Este valor foi multiplicado pelo peso calculado para cada ação na MVP pelo método de otimização de média-variância e dividido pela cotação de fechamento da ação no dia anterior, o último dia do quadrimestre anterior, que foi usado para estimar os pesos, como se a ação tivesse sido comprada por este preço neste dia. Diariamente a quantidade teórica de cada ação calculada no primeiro dia do quadrimestre foi multiplicada pelo preço de fechamento da ação no dia como na equação 3. A soma da quantidade de cada ação multiplicada pelo respectivo preço forneceu o valor do índice para cada um dos dias do período de análise do desempenho. Assim como no IBOVESPA, as MVPs não foram rebalanceadas diariamente. Esta metodologia faz com que o peso de cada ativo na carteira se altere diariamente de acordo com as oscilações do preço de fechamento de cada ação.

$$
\begin{gathered}
Q_{i, q}=\frac{M V P_{t-1} \times w_{i, q}}{P_{i, q}} \\
M V P_{t}=\sum_{i=1}^{N} P_{i, t} \times Q_{i, q}
\end{gathered}
$$

Onde:

$M V P_{t}=$ Índice MVP no dia $t$, sendo que $M V P_{0}=100.000$;

$N=$ número total de ações na carteira teórica;

$P_{i, t}=$ último preço da ação $i$ no dia $t$;

$Q_{i, q}=$ quantidade teórica da ação $i$ no quadrimestre $q$ em que está o dia $t$;

$w_{i, q}=$ peso da ação na $M V P$ no primeiro do quadrimestre

$q$ calculado com dados do quadrimestre anterior.

Do segundo quadrimestre em diante, o valor do índice no final do quadrimestre anterior foi multiplicado pelos novos pesos de cada ação, referentes ao novo quadrimestre e calculados com base no quadrimestre anterior, e dividido pelo preço de cada ação no último dia do quadrimestre anterior para determinar a nova quantidade teórica de cada ação a viger no novo quadrimestre. Este processo de cálculo da quantidade de cada ativo e do valor do

\footnotetext{
${ }^{2}$ Acesso em 13 de setembro de $2010<$ http://wis.kuleuven.be/stat/robust.html $>$.
} 
índice se repetiu até o último dia do estudo. A partir do valor diário de cada um dos índices foi possível calcular seu retorno diário $\left(M V P_{t} / M V P_{t-1}-1\right)$ e acumulado $\left(M V P_{t} / M V P_{1}-1\right)$.

$\mathrm{O}$ value at risk $(\mathrm{VaR})$, ou valor em risco, histórico foi calculado a um nível de 99 por cento de significância como medida complementar ao desviopadrão das MVPs. Este indicador consiste em empregar determinado quantil da distribuição empírica dos retornos para estimar a maior perda diária possível com 99 por cento de segurança. Este estudo usou o percentil 1 por cento. A equação 4 mostra a fórmula de cálculo. $\mathrm{O} V a R_{\alpha}$ e a perda $l$ que uma carteira pode ter, cuja probabilidade de uma perda $L$ excedê-la é menor ou igual a $(1-\alpha)$. O VaR $\alpha$ e um percentil da distribuição de perdas.

$$
\operatorname{VaR}_{\alpha}=\inf \{l \in \mathbb{R}: P(L>l) \leq 1-\alpha\}
$$

O teste não paramétrico da soma das ordens de Wilcoxon foi usado para avaliar a diferença estatística entre as séries de retornos. Levine et al. (2005) asseguram que este teste é amplamente empregado e é provavelmente mais eficaz do que o teste $t$ quando não se pode afirmar que os dados apresentam uma distribuição normal. Triola (2005) afirma que é preciso supor que a amostra analisada possui distribuição normal para usar o coeficiente de correlação de Pearson. O coeficiente de correlação de Spearman é uma estatística não paramétrica que não requer suposições acerca da distribuição dos dados e que permite detectar relações não lineares e foi, portanto, usado como a medida de correlação neste estudo.

\section{Resultados}

\subsection{Comparação das MVP com o IBOVESPA}

A Tabela 1 apresenta um resumo estatístico do desempenho dos índices no período total. A carteira com peso máximo de dez por cento por ação apresentou desvio-padrão menor do que a carteira sem limite para os pesos. Todas as MVP apresentaram desvio-padrão menor do que o do IBOVESPA, como seria de se esperar. O VaR não paramétrico com 99 por cento de significância dos índices de mínima variância são semelhantes entre si e inferiores ao do IBOVESPA. Todas as MVP superaram o retorno do IBOVESPA. Quanto maior o limite sobre o peso da ação maior o retorno observado. A MVP com pesos limitados a dez por cento da carteira foi a que apresentou o melhor retorno e a melhor relação retorno sobre risco. O IBOVESPA é o índice que apresenta a maior incidência de valores extremos. Não há uma tendência clara de comportamento das MVP quanto aos valores extremos em relação aos limites impostos sobre os pesos. A incidência de retornos diários negativos é similar entre os diversos índices. A Tabela 1 também mostra que as MVP são formadas por menos do que um terço do número de ações que o IBOVESPA. A redução no número de ativos diminui os custos de gestão das carteiras. O número médio de ativos em cada MVP aproxima-se de 14 em todos os casos, próximo de 12, que é o número considerado ideal por Ceretta \& Costa Jr. (2000). A lista com o número de ações de cada MVP em cada quadrimestre está disponível com os autores. O teste da soma das ordens de Wilcoxon indica que somente os retornos da MVP com pesos máximos de dez por cento são marginalmente diferentes dos retornos do IBOVESPA. Todas as MVP apresentam correlação alta, positiva e significativa ao nível de 1 por cento com o IBOVESPA. 
A Figura 1 apresenta o retorno diário acumulado do IBOVESPA e das cinco MVP para o período de 30 de abril de 1998 até 30 de dezembro de 2008. É possível perceber que, como esperado, todos os índices de mínima variância possuem comportamento semelhante, começando a se distanciar do IBOVESPA a partir de 2001. A desvalorização da ação Embratel Participações ON (EBTP3) no final de 2004 prejudicou significativamente o desempenho das carteiras com restrições de 50 , de 75 por cento e sem restrições porque constituía grande parte delas. A imposição de um peso máximo por ação preservou o desempenho das MVP com os limites de dez e 25 por cento. Todos as MVP sofreram perdas significativas com os efeitos provenientes da crise do subprime.

Tabela 1: Estatísticas descritivas para as carteiras de mínima variância global com pesos máximos variados, para o Ibovespa e para dois fundos de ações selecionados no período entre abril de 1998 e dezembro de 2008.

\begin{tabular}{|c|c|c|c|c|c|c|}
\hline \multicolumn{7}{|c|}{ Peso Máximo por Ação na MVP } \\
\hline & 10 & 25 & 50 & 75 & 100 & Ibovespa \\
\hline $\begin{array}{l}\text { Retorno } \\
\text { acumulado (\%) }\end{array}$ & 632,8500 & 465,5600 & 383,7000 & 317,6500 & 315,5300 & 221,5700 \\
\hline $\begin{array}{l}\text { Retorno diário } \\
\text { médio }(\%)\end{array}$ & 0,0754 & 0,0656 & 0,0597 & 0,0541 & 0,0539 & 0,0442 \\
\hline Desvio padrão & 0,0165 & 0,0165 & 0,0166 & 0,0167 & 0,0167 & 0,0236 \\
\hline VaR $99(\%)$ & 4,5320 & 4,4952 & 4,6755 & 4,6765 & 4,6765 & 6,2578 \\
\hline $\begin{array}{l}\text { Ret. Médio Dia/ } \\
\text { Desvio-Padrão }\end{array}$ & 0,0457 & 0,0399 & 0,0360 & 0,0324 & 0,0323 & 0,0188 \\
\hline Assimetria & $-0,0625$ & $-0,1312$ & $-0,1469$ & $-0,2266$ & $-0,2305$ & 1,1843 \\
\hline Curtose & 4,8194 & 4,1812 & 4,0917 & 4,5124 & 4,5393 & 19,7282 \\
\hline Mediana & 0,1104 & 0,0998 & 0,1021 & 0,1024 & 0,1024 & 0,1147 \\
\hline Retorno mínimo (\%) & $-11,1100$ & $-10,4900$ & $-9,9200$ & $-10,7900$ & $-10,9300$ & $-15,8300$ \\
\hline Retorno máximo (\%) & 12,2700 & 11,4400 & 11,4400 & 11,4400 & 11,4400 & 33,4000 \\
\hline $\begin{array}{l}\text { Retornos } \\
\text { negativos (\%) }\end{array}$ & 47,5600 & 46,6500 & 46,6500 & 46,3900 & 46,3900 & 47,8200 \\
\hline Retornos $>2,5 \%(\%)$ & 5,3700 & 5,4100 & 5,6800 & 5,6800 & 5,6800 & 9,5300 \\
\hline Retornos $<-2,5 \%(\%)$ & 4,9600 & 4,5000 & 4,9200 & 5,0300 & 5,0300 & 10,4000 \\
\hline Retornos $>5 \%(\%)$ & 0,6800 & 0,6100 & 0,4900 & 0,4900 & 0,4900 & 1,5900 \\
\hline Retornos $<-5 \%(\%)$ & 0,6800 & 0,7900 & 0,8300 & 0,8300 & 0,8300 & 1,7400 \\
\hline $\begin{array}{l}\mathrm{N}^{\circ} \text { médio de } \\
\text { ações carteira }\end{array}$ & 15,8800 & 13,0900 & 12,6300 & 12,6300 & 12,6300 & 56,0000 \\
\hline $\begin{array}{l}\text { Teste de } \\
\text { Wilcoxon }\left(Z_{a}\right)\end{array}$ & 1,7890 & $-1,0100$ & $-0,6840$ & $-0,6180$ & $-0,6170$ & $\mathrm{n} / \mathrm{a}$ \\
\hline $\begin{array}{l}\text { Wilcoxon } \\
\text { (p-valor) }\end{array}$ & 0,0720 & 0,3120 & 0,4940 & 0,5370 & 0,5370 & $\mathrm{n} / \mathrm{a}$ \\
\hline $\begin{array}{l}\text { Correlação } \\
\text { (Spearman) }\end{array}$ & 0,8350 & 0,7710 & 0,7740 & 0,7450 & 0,7440 & $\mathrm{n} / \mathrm{a}$ \\
\hline $\begin{array}{l}\text { a: Os testes de Wilcc } \\
\text { MVP 10). Todos o } \\
\text { dizer "não se aplic } \\
\text { subtrair } 3 \text {. Neste } \\
\text { em relacão à curv }\end{array}$ & ficientes & correlaç & ão signi & IIV d & tivas (Ib & $\begin{array}{l}\text { spa }> \\
\text { a"quer } \\
\text { al deve-se } \\
\text { negativa }\end{array}$ \\
\hline
\end{tabular}

A Tabela 2 apresenta a frequência com que cada um dos índices de mínima variância superou o retorno e o desvio-padrão do IBOVESPA. O Painel A da Tabela 2 mostra os resultados para períodos selecionados fixos e não superpostos. Os índices de mínima variância superaram o retorno do IBOVESPA na maioria dos períodos. As MVPs superaram o IBOVESPA mais frequentemente nos períodos mais longos. A MVP com limite de dez por cento de peso 


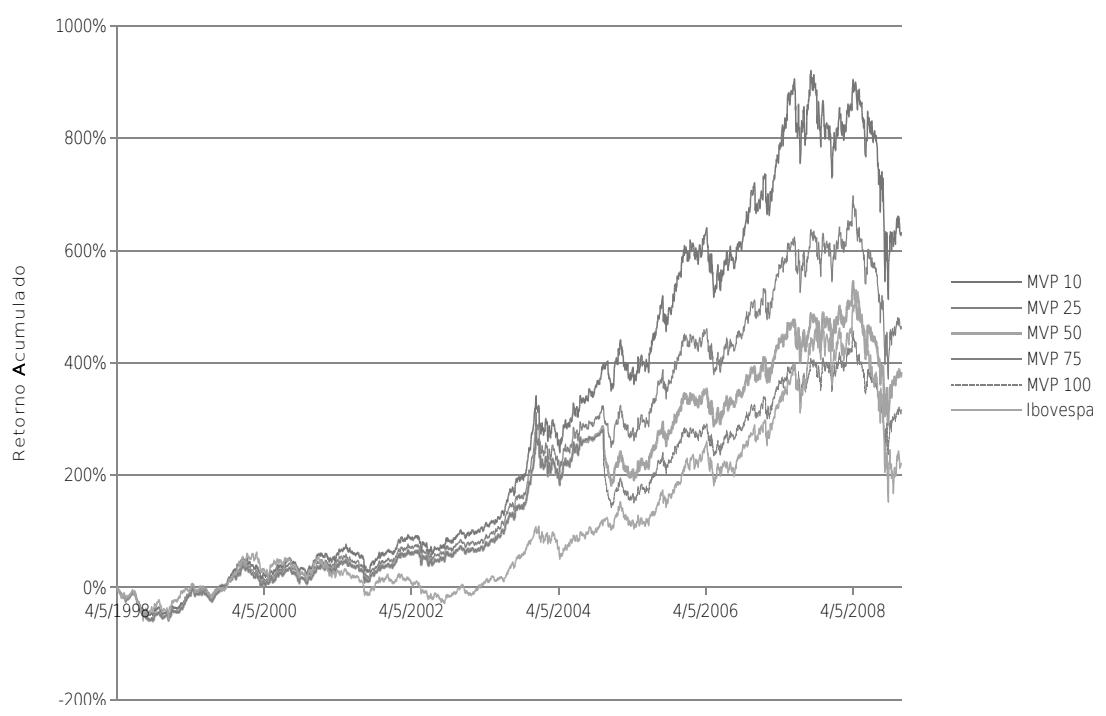

Figura 1: Retorno acumulado para o IBOVESPA e carteiras de mínima variância com diversos pesos máximos por ativo de abril de 1998 a dezembro de 2008

por ação superou o IBOVESPA em 63,64 por cento dos quadrimestres. Todas as MVPs apresentaram desvio-padrão menor do que o do IBOVESPA em pelo menos em 95,45 por cento dos períodos analisados. A MVP com limite de dez por cento nos pesos das ações apresentou desvio-padrão menor do que o do IBOVESPA em todos os períodos analisados.

O Painel B da Tabela 2 apresenta uma análise alternativa com janelas que se movem um dia de cada vez de tamanho igual a 21, 42, 63, 126, 252 e 504 dias úteis. O objetivo desta análise adicional foi aumentar o número de períodos. Verificou-se o percentual de vezes em que o retorno das carteiras de mínima variância foram superiores ao retorno do IBOVESPA e o percentual de vezes em que o desvio-padrão das carteiras de mínima variância foram inferiores ao desvio-padrão do IBOVESPA. Os resultados são qualitativamente os mesmos que os obtidos no Painel A da Tabela 2 para períodos fixos e não superpostos. Os desvios-padrão calculados a partir de períodos superpostos no painel B são muito próximos dos desvios-padrão calculados a partir de períodos não superpostos do painel $\mathrm{A}$ e, por isso, não foram estimados com correção para a autocorrelação.

\subsection{Comparação da MVP com fundos de ações}

Os resultados da seção anterior sugerem que a MVP com peso máximo de dez por cento apresenta desempenho superior ao do IBOVESPA. Por isso, cinquenta e seis fundos de ações com gestão ativa foram selecionados para uma nova rodada de comparações com a MVP com peso máximo de dez por cento. Foram considerados apenas os fundos classificados pela Associação Brasileira das Entidades dos Mercados Financeiro e de Capitais (Anbima) como "Ações IBOVESPA Ativo" porque eles têm como objetivo superar o IBOVESPA na base da dados Quantum Axis ${ }^{\circledR}$. Foram considerados tanto fundos que não admitem alavancagem quanto os que a empregam porque ambos podem usar a 
Tabela 2: Percentual de períodos em que cada MVP supera o retorno e o desvio-padrão do Ibovespa entre abril de 1998 e dezembro de 2008

\begin{tabular}{|c|c|c|c|c|c|c|c|}
\hline & $\begin{array}{l}\text { Tamanho } \\
\text { do Período } \\
\text { em Dias de } \\
\text { Negociação }\end{array}$ & $\begin{array}{l}\text { Número de } \\
\text { Amostras }\end{array}$ & & o Máxim & 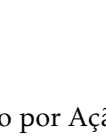 & ão na MV & \\
\hline & & & 10 & 25 & 50 & 75 & 100 \\
\hline & & inel A: segund & o períod & s fixos e & não supe & rpostos & \\
\hline \multirow[t]{5}{*}{ Retorno } & 1 & 2643 & 51,08 & 50,59 & 50,47 & 50,40 & 50,40 \\
\hline & 30 & 88 & 54,55 & 48,86 & 48,86 & 47,73 & 47,73 \\
\hline & 60 & 44 & 59,09 & 59,09 & 61,36 & 61,36 & 61,36 \\
\hline & 90 & 29 & 62,07 & 58,62 & 58,62 & 58,62 & 58,62 \\
\hline & 120 & 22 & 63,64 & 54,55 & 54,55 & 54,55 & 54,55 \\
\hline \multirow[t]{5}{*}{ Desvio-Padrão } & 30 & 88 & 100,00 & 100,00 & 96,59 & 96,59 & 96,59 \\
\hline & 60 & 44 & 100,00 & 97,73 & 95,45 & 95,45 & 95,45 \\
\hline & 90 & 29 & 100,00 & 100,00 & 96,67 & 96,67 & 96,67 \\
\hline & 120 & 22 & 100,00 & 100,00 & 100,00 & 95,45 & 95,45 \\
\hline & Paine & el B: segundo & anelas qu & e se mov & em um di & ia por vez & \\
\hline \multirow[t]{7}{*}{ Retorno } & 1 & 2643 & 51,08 & 50,59 & 50,47 & 50,40 & 50,40 \\
\hline & 21 & 2623 & 53,95 & 51,35 & 51,54 & 51,58 & 51,58 \\
\hline & 42 & 2602 & 55,96 & 52,61 & 52,38 & 52,50 & 52,50 \\
\hline & 63 & 2581 & 56,99 & 53,24 & 53,20 & 53,31 & 53,31 \\
\hline & 126 & 2518 & 57,27 & 52,90 & 52,22 & 52,10 & 52,10 \\
\hline & 252 & 2392 & 59,03 & 45,65 & 43,14 & 43,02 & 43,02 \\
\hline & 504 & 2140 & 65,98 & 56,03 & 48,60 & 48,46 & 48,46 \\
\hline \multirow[t]{6}{*}{ Desvio-Padrão } & 21 & 2623 & 97,64 & 95,77 & 94,36 & 94,32 & 94,32 \\
\hline & 42 & 2602 & 99,27 & 97,58 & 96,00 & 95,81 & 95,81 \\
\hline & 63 & 2581 & 100,00 & 97,29 & 95,74 & 94,69 & 94,65 \\
\hline & 126 & 2518 & 100,00 & 99,56 & 99,52 & 94,52 & 94,52 \\
\hline & 252 & 2392 & 100,00 & 100,00 & 100,00 & 99,79 & 99,75 \\
\hline & 504 & 2140 & 100,00 & 100,00 & 100,00 & 100,00 & 100,00 \\
\hline
\end{tabular}

MVP com peso máximo de dez por cento como padrão de comparação. Em seguida foram considerados apenas os fundos com cota entre 30/4/1998 e $31 / 12 / 2008$. Este critério introduz um viés de sobrevivência que dificulta a aceitação da hipótese da MVP ter desempenho superior aos fundos, o que não representa um problema para a análise. A amostra ficou com 56 fundos. A relação desses fundos e sua comparação com a MVP com peso máximo de dez por cento encontram-se nas tabelas incluídas no Apêndice. Os retornos da MVP com peso máximo de dez por cento, naturalmente, não sofrem desconto de uma taxa de administração. As cotas dos fundos, contudo, são líquidas dessas taxas. As cotas dos fundos foram recompostas usando a taxa de administração mais recente reportada para ser possível comparar os retornos dos fundos com os da MVP com peso máximo de dez por cento. Verificamos se as taxas de administração mais recentes eram diferentes das taxas do início do período amostral, mas não contatamos nenhum caso de alteração de taxa na amostra. As taxas de performance também reduzem os retornos dos fundos, mas sua recomposição não é tão simples e, por isso, não foram consideradas. Na Tabela A.1 do Apêndice pode se ver que apenas 12 dos 56 fundos cobravam taxa de performance, todas em relação ao IBOVESPA. A recomposição das taxas de administração foi feita segundo a equação 5 , onde $C A_{t}$ é a cota ajustada no dia $t$ para a taxa de administração $(f)$ e $C_{t}$ é a cota reportada pelo fundo no dia $t$. Para iniciar a série, considerou-se $C A_{0}=C_{0}$. A taxa de administração considerada foi a última reportada pelo fundo. 


$$
C A_{t}=C A_{t-1} \times \frac{C_{t}}{C_{t-1}} \times\left(\frac{1+f}{252}\right)
$$

A Tabela 3 apresenta a frequência com que os fundos de ações que superaram o retorno do MVP com peso máximo de 10 por ação em mais da metade das janelas móveis analisadas entre abril de 1998 e dezembro de 2008. Há um contingente entre 7 e 28 fundos, dependendo da janela empregada, que supera a MVP com peso máximo de dez por cento. Excetuando-se a janela com tamanho de um dia, não há uma relação clara entre o tamanho da janela e o número de fundos que supera o retorno da MVP com peso máximo de dez por cento no mesmo período. Também não se pode inferir que os fundos que a superam sejam predominantemente os que empregam alavancagem. Contudo, para as janelas mais longas, os fundos vencedores superam a MVP com peso máximo de dez por cento com mais frequência. Os fundos vencedores em cada tamanho de janela apresentam desvio-padrão menor do que a MVP com peso máximo de dez por cento com muita frequência. Os resultados da Tabela 3 sugerem que há um grupo de fundos que é capaz de superar uma regra simples de investimento como a empregada pela MVP com peso máximo de dez por cento expondo-se a uma volatilidade menor. O leitor interessado pode verificar quais foram estes fundos no Apêndice.

Tabela 3: Fundos de ações que superaram o retorno do MVP com peso máximo de 10 por ação em mais da metade das janelas móveis analisadas entre abril de 1998 e dezembro de 2008

\begin{tabular}{|c|c|c|c|c|}
\hline $\begin{array}{l}\text { Tamanho } \\
\text { da janela } \\
\text { em dias de } \\
\text { Negociação }\end{array}$ & No fundos & $\begin{array}{l}\mathrm{N}^{\circ} \text { de } \\
\text { fundos } \\
\text { alavan- } \\
\text { cados }\end{array}$ & $\begin{array}{l}\text { Percentual mé- } \\
\text { dio de vezes em } \\
\text { que o retorno foi } \\
\text { superado }\end{array}$ & $\begin{array}{l}\text { Percentual médio de ve- } \\
\text { zes em que o desvio- } \\
\text { padrão do MVP foi su- } \\
\text { perado quando o re- } \\
\text { torno foi superado }\end{array}$ \\
\hline 1 & 28 & 10 & 50,55 & $\mathrm{n} / \mathrm{a}$ \\
\hline 21 & 10 & 6 & 51,96 & 38,92 \\
\hline 42 & 11 & 5 & 52,74 & 36,25 \\
\hline 63 & 12 & 6 & 52,88 & 34,27 \\
\hline 126 & 12 & 7 & 54,61 & 30,77 \\
\hline 252 & 17 & 7 & 55,55 & 19,51 \\
\hline 504 & 7 & 3 & 61,86 & 41,82 \\
\hline
\end{tabular}

\subsection{Testes de Robustez}

Os testes de robustez se concentrarão na MVP com pesos limitados a dez por cento porque foi a carteira que apresentou melhores resultados. O IBOVESPA apresenta mais valores extremos do que a MVP e é possível que eles sejam responsáveis pela diferença entre os dois índices. Foram excluídos os dez maiores e os dez menores retornos diários do IBOVESPA, mas a exclusão não modificou qualitativamente os resultados obtidos anteriormente. A MVP com pesos máximos de dez por cento continuou superando o IBOVESPA quanto 
ao retorno diário médio (0,0786 e 0,0364 por cento, respectivamente). Houve redução do desvio-padrão do IBOVESPA para 0,0205, que ainda é bem maior que o da MVP selecionada. Os dias de retornos extremos excluídos do IBOVESPA também foram excluídos da MVP. O teste de Wilcoxon aplicado aos retornos remanescentes ainda foi significativo a dez por cento $\left(Z_{a}=1,832\right) \mathrm{e}$ a correlação entre os índices permaneceu elevada $(0,831)$. O boxplot das duas carteiras, que não foi incluído no artigo, mas que está disponível com os autores, mostra que a MVP selecionada apresenta uma distribuição de retornos diários menos dispersa.

A MVP com pesos limitados a dez por cento foi recalculada com os preços médios de cada dia. Os resultados continuaram qualitativamente os mesmos. Talvez os preços médios do dia levassem a resultados diferentes porque as cotações de fechamento refletem somente um momento do dia e podem ser alteradas por um único investidor. O retorno diário médio variou de 0,0754 por cento com os preços de fechamento para 0,0745 por cento com os preços médios. O desvio-padrão foi de 0,0165 com os preços de fechamento e passou para 0,0164 os preços médios. O teste de Wilcoxon para a diferença entre os retornos diários da MVP selecionada e o IBOVESPA deixou de ser marginalmente significativo. A estatística $Z_{a}$ resultou em -1,370 e não foi mais possível afirmar que existisse diferença estatística entre a MVP selecionada e o IBOVESPA. A correlação entre os índices aumentou para 0,963.

DeMiguel et al. (2009) afirmam que nenhuma forma de se calcular os pesos das carteiras eficientes supera uma alocação ingênua com pesos iguais em cada ativo $(1 / N)$. Um índice igualmente ponderado foi calculado com as mesmas ações que foram incluídas na MVP sem limites sobre os pesos. A Tabela 4 mostra que este índice igualmente ponderado apresenta retorno diário médio e desvio-padrão dos retornos diários maiores do que os das MVP com pesos limitados a dez por cento e sem limites de peso. A relação retorno médio dividido pelo desvio-padrão do índice igualmente ponderado é essencialmente a mesma do que a da MVP com pesos limitados a dez por cento.

Tabela 4: Estatísticas descritivas para as MVP com peso máximo de 10 (MVP 10), sem limites sobre os pesos (MVP 100), uma carteira igualmente ponderada com as mesmas ações da MVP $100(1 / \mathrm{N})$ e a MVP com peso máximo de 10 estimada com uma matriz de covariâncias robusta (MVP $10 \mathrm{R}$ )

\begin{tabular}{lrrrr}
\hline & MVP 10 & MVP 100 & \multicolumn{1}{c}{$1 / \mathrm{N}$} & MVP 10 R \\
\hline Retorno Acumulado (\%) & 632,8500 & 315,5300 & 713,4700 & 445,2200 \\
Retorno diário médio (\%) & 0,0754 & 0,0539 & 0,0793 & 0,0642 \\
Desvio-padrão & 0,0165 & 0,0167 & 0,0173 & 0,0164 \\
VaR 99 (\%) & 4,5320 & 4,6765 & 4,7673 & 4,4637 \\
Ret. Méd. Dia/Desv. Pad. & 0,0457 & 0,0323 & 0,0458 & 0,0390 \\
\hline
\end{tabular}

Não é possível afirmar que a carteira igualmente ponderada apresenta desempenho significativamente diferente das MVP selecionadas. As estatísticas de Wilcoxon não apresentaram significância estatística para a MVP com pesos limitados a dez por cento $(-0,023)$ e para a MVP sem limitação sobre os pesos $(-1,222)$. O coeficiente de correlação de Spearman é elevado entre estes índices, sendo de 0,963 e 0,926 para a MVP com pesos limitados a dez por 
cento e para a MVP sem limites sobre os pesos, respectivamente. Estes resultados similares aos da MVP com pesos máximos de dez por cento favorece a hipótese de que alocações simples são vantajosas. A Tabela 1 indica que o número médio de ativos que compõem a carteira igualmente ponderada $(12,63$ ativos) é menor do que o número médio de ativos que compõem a MVP com pesos limitados a dez por cento $(15,88$ ativos). Uma carteira com pesos iguais e com menos ativos do que a MVP de melhor desempenho é uma forte indicação de que regras que limitem os pesos e o número de ativos considerados apresentam resultados difíceis de serem superados. Contudo, não se deve esquecer que a carteira igualmente ponderada usada nesta análise partiu das ações selecionadas pela otimização de média-variância de Markowitz (1952) para compor a MVP sem limites máximos de peso.

Uma nova MVP com pesos máximos de dez por cento foi obtida com base no método proposto por Mendes \& Leal (2005) para o cálculo de uma matriz de covariância robusta. O retorno acumulado da MVP com pesos máximos de dez por cento calculada com a matriz de covariâncias amostral supera o retorno acumulado da mesma MVP calculada com a matriz de covariâncias robusta. O desvio-padrão e o $V a R$ das duas carteiras são similares. Os retornos diários da MVP robusta são significativamente menores do que os da MVP clássica, mas não são significativamente diferentes dos retornos do IBOVESPA. A estatística de Wilcoxon foi de $-2,634$ e $-1,505$, respectivamente, para estes dois índices. Esse resultado difere do encontrado por Mendes \& Leal (2005) porque aponta que a metodologia robusta não é superior. Essa divergência pode ser resultado da imposição de um peso máximo por ação e da restrição ao número de ações que compõem a MVP robusta, uma vez que aqueles autores não impõem essa restrição.

Em suma, os resultados que indicam a superioridade da MVP com pesos limitados a dez por cento em relação ao IBOVESPA não parecem ser devidos aos valores extremos, ao uso de preços de fechamento ou à forma como a matriz de covariâncias foi calculada. Esta MVP também apresenta resultados similares aos da carteira igualmente ponderada composta por ações selecionadas para compor a MVP sem limites sobre os pesos. Neste último caso, não se pode afirmar que ela supere uma carteira igualmente ponderada, embora a carteira igualmente ponderada seja formada por menos ativos do que MVP com pesos limitados a dez por cento, o que representa uma vantagem para a primeira.

\section{Conclusões}

A carteira de mínima variância global com limites máximos impostos sobre os pesos das ações foi capaz de apresentar retorno médio maior com desviopadrão menor do que o IBOVESPA. Esta grande vantagem é atenuada pelos testes estatísticos não paramétricos que não indicam que os retornos destas carteiras são diferentes dos retornos do IBOVESPA, com a exceção da carteira de mínima variância global com pesos limitados a dez por cento. Esta restrição garantiu uma alocação mais estável e uniforme para as ações nesta carteira em cada quadrimestre. Ela apresentou o maior retorno acumulado e o segundo menor desvio-padrão entre as carteiras de mínima variância global e se destacou na frequência com que superou os retornos do IBOVESPA. Este resultado é consistente com a evidência apresentada por DeMiguel et al. (2009) 
de que limites sobre os pesos dos ativos nas carteiras e sobre o número total de ativos considerados são medidas eficazes. O número médio de ações na carteira de mínima variância global com pesos limitados a dez por cento é consistente com a recomendação para o número máximo de ações em um carteira para que se diversifique bem o risco sugerido por Ceretta \& Costa Jr. (2000) para o mercado brasileiro. Estas limitações também ajudam a reduzir o custo de gestão da carteira.

Os testes de robustez mostraram que a vantagem da carteira de mínima variância global com pesos limitados a dez por cento sobre o IBOVESPA é significativa e consistente. Ela continuou a superar o IBOVESPA estatisticamente mesmo quando os retornos atípicos foram removidos da amostra. $O$ uso de preços médios diários no lugar dos preços de fechamento não alterou os resultados. O emprego de uma matriz de covariâncias robusta, em conjunto com o peso limitado em dez por cento, não melhorou os resultados.

A comparação entre a carteira de mínima variância global com pesos limitados a dez por cento e uma carteira com pesos iguais para as ações selecionadas para a carteira de mínima variância global sem limite sobre o peso das ações não foi conclusiva a favor de uma ou outra. DeMiguel et al. (2009) afirmam que a carteira igualmente ponderada supera todas as carteiras calculadas por meio de diversos métodos mais complexos, incluindo a própria carteira de mínima variância global sem limitar o peso de cada ativo. Os resultados deste estudo para a carteira de mínima variância global sem imposição de limites são consistentes com os resultados destes autores. No entanto, a cabe destacar que a carteira de mínima variância global com pesos limitados a dez por cento apresentou risco menor do que o da carteira igualmente ponderada, com relação retorno-risco praticamente igual, mas contava com mais ativos, na média, do que esta última.

A carteira de mínima variância global com pesos limitados a dez por cento foi comparada a 56 fundos de ações ativos que adotam ou não alavancagem. Os retornos observados para os fundos foram ajustados a sua taxa de administração. Dependendo do tamanho da janela empregada, há um contingente relevante de fundos de ações com gestão ativa que supera o retorno da carteira de mínima variância global com pesos limitados a dez por cento, apresentando volatilidade frequentemente menor. $O$ uso de alavancagem pelos fundos não parece ser um fator que influencie no tipo de fundo vencedor neste caso. Os fundos de ações que foram extintos durante o período analisado eram provavelmente os de baixo desempenho. Os fundos empregados nessas comparações, portanto, eram sobreviventes. Por outro lado, como não se ajustou o retorno dos fundos às taxas de performance, pode ser que houvesse um número maior a superar a carteira de mínima variância global com pesos limitados a dez por cento.

O número elevado de ações excluídas nos primeiros quadrimestres pode ter contribuído para que o desempenho dos índices de mínima variância não tenham se destacado do IBOVESPA nos primeiros períodos do estudo. A exclusão de ativos reduz o número de combinações possíveis na carteira. É possível ter havido um viés de sobrevivência favorável aos índices de mínima variância se os ativos excluídos eram os de desempenho pior. Por outro lado, as carteiras de mínima variância global superaram o IBOVESPA na maior parte dos 22 quadrimestres analisados enquanto os quadrimestres com um número maior de exclusões foram apenas cinco.

As carteiras de mínima variância globais foram calculadas a cada quadri- 
mestre, seguindo o procedimento do IBOVESPA. Trabalhos futuros poderiam investigar se frequências maiores ou menores de recálculo dos pesos teriam influência sobre os resultados aqui apresentados. Atualizações mais frequentes permitiriam a inclusão mais rápida de ações provenientes de IPOs, por exemplo, mas elevariam o custo de gestão da carteira. A análise apresentada foi limitada às ações mais negociadas e que compõem o IBOVESPA, tendo em mente a simplicidade. Uma extensão natural do estudo seria examinar o impacto da inclusão de ativos internacionais, ETFs que repliquem índices de ações de alguns dos maiores mercados globais, por exemplo, para investigar se é benéfica para os investidores a criação de mais uma referência de desempenho para o mercado.

Os resultados apresentados sugerem que criar um exchange-traded fund (ETF) baseado na carteira de mínima variância global com pesos limitados pode gerar um produto financeiro atraente, uma vez que parece superar o IBOVESPA. A estratégia também pode ser facilmente replicada por clubes de investimento e até por investidores individuais que se disponham a fazer o cálculo dos pesos a cada quadrimestre, um problema facilmente solucionável com uma planilha Excel ${ }^{\circledR}$. Um índice de mínima variância também poderia ser desenvolvido e poderia ser empregado como referência de desempenho alternativa ao índice IBOVESPA. Por outro lado, fica claro que uma carteira igualmente ponderada composta por cerca de 12 ações, dentre aquelas do IBOVESPA, que apresentem os melhores índices de Sharpe também será um benchmark difícil de ser superado. Finalmente, cabe dizer que a gestão ativa dos fundos analisados tem mérito e, em muitos casos, superou a estratégia mais simples da carteira de mínima variância global com pesos limitados a dez por cento.

\section{Referências Bibliográficas}

Almeida, V. S. (2012), 'Are betas best? the correlation structure on brazilian equity market.', Journal of International Finance and Economics . forthcoming.

Ang, A., Hodrick, Robert, J., Xing, Y. \& Zhang, X. (2006), 'The cross-section of volatility and expected returns', The Journal of Finance 61(1), 259-299.

Arditti, F. D. \& Levy, H. (1975), 'Portfolio efficiency analysis in three moments: The multi-period case', The Journal of Finance 30(3), 797-809.

Bauer, R., Haerden, R. \& Molenaar, R. (2004), 'Asset allocation in stable and unstable times', Journal of Investing 13(3), 72-80.

Best, M. J. \& Grauer, R. R. (1991), 'On the sensitivity of mean-variance efficient portfolios to changes in asset means: some analytical and computational results', The Review of Financial Studies 4(2), 315-342.

Black, F. \& Litterman, R. (1991), 'Asset1 allocation: combining investors views with market equilibrium', Journal of Fixed Income 1(2), 7-18.

Bloomfield, T., Leftwich, R. \& Long John, J. (1977), 'Portfolio strategies and performance', Journal of Financial Economics 5(2), 210-218.

Ceretta, P. S. \& Costa Jr., N. C. A. (2000), Quantas ações tornam um portfólio diversificado no mercado de capitais brasileiro?, in N. C. A. Costa, Jr, 
R. P. C. Leal \& E. F. Lemgruber, eds, 'Mercado de Capitais: Análise Empírica no Brasil', Atlas.

Clarke, R., de Silva, H. \& Thorley, S. (2006), 'Minimum-variance portfolios in the u.s. equity market', The Journal of Portfolio Management 33(1), 10-24.

Constantinides, G. M. \& Malliaris, A. G. (1995), Portfolio theory, in R. A. Jarrow, V. Maksimovic \& W. T. Ziemba, eds, 'Handbooks in operations research and management science: Finance', Vol. 9, North-Holland: Elsevier.

DeMiguel, V., Garlappi, L. \& Uppal, R. (2009), 'Optimal versus naive diversification: how inefficient is the $1 / \mathrm{n}$ portfolio strategy?', The Review of Financial Studies 22(5), 1915-1953.

Disatnik, D. J. \& Benninga, S. (2007), 'Shrinking the covariance matrix optimal versus naive diversification: how inefficient is the $1 / \mathrm{n}$ portfolio strategy?', The Journal of Portfolio Management 33(4), 55-63.

Fletcher, J. \& Hillier, J. (2001), 'An examination of resampled portfolio efficiency', Financial Analysts Journal 57(5), 66-74.

Gohout, W. \& Specht, K. (2007), 'Mean-variance portfolios using bayesian vector-autoregressive forecasts', Statistical Papers 48(3), 403-418.

Green, R. C. \& Hollifield, B. (1992), 'When will mean-variance efficient portfolios be well diversified?', The Journal of Finance 47(5), 1785-1809.

Handa, P. \& Tiwari, A. (2006), 'Does stock return predictability imply improved asset allocation and performance? - evidence from the us stock market (1954-2002)', The Journal of Business 79(5), 2423-2468.

Harvey, C., Liechty, J. \& Liechty, M. (2008), 'Bayes vs. resampling: a rematch', Journal of Investment Management 6(1), 1-17.

Harvey, C., Liechty, J., Liechty, M. \& Muller, P. (2010), 'Portfolio selection with higher moments', Quantitative Finance 10(5), 469-485.

Jobson, J. D. \& Korkie, B. (1981), 'Putting markowitz theory to work', The Journal of Portfolio Management 7(4), 70-74.

Kahneman, D. \& Tversky, A. (1979), 'Prospect theory: An analysis of decision under risk', Econometrica 47(2), 263-291.

Leal, R. P. C. \& Mendes, B. V. M. (2010), 'Incorporating tail dependence into markowitz mean-variance model', Unpublished Working Paper, Instituto Coppead de Administração/UFRJ.

Ledoit, O. \& Wolf, M. (2004), 'Honey, i shrunk the sample covariance matrix', The Journal of Portfolio Management 30(4), 110-119.

Levine, D. M., Stephan, D. F., Krehbiel, T. C. \& Berenson, M. L. (2005), Estatística: teoria e aplicações, 3 edn, LTC.

Markowitz, H. (1952), 'Portfolio selection', The Journal of Finance 7(1), 77-91.

Mendes, B. V. M. \& Leal, R. P. C. (2005), 'Robust multivariate modeling in finance', International Journal of Managerial Finance 1(2), 95-107. 
Mendes, B. V. M. \& Leal, R. P. C. (2010), 'Portfolio management with semiparametric bootstrapping', Journal of Risk Management in Financial Institutions 3(2), 174-183.

Michaud, R. O. (1989), 'The markowitz optimization enigma: is "optimized"optimal?', Financial Analysts Journal 45(1), 31-42.

Michaud, R. O. (1998), Efficient asset management: a practical guide to stock portfolio optimization and asset allocation, 1 edn, Harvard Business School Publishing.

Oliveira, F. N. \& De Paula, E. L. (2008), 'Determinando o grau ótimo de diversificação para investidores usuários de home brokers', Revista Brasileira de Finanças 6(3), 437-461.

Rousseeuw, P. J. (1984), 'Least median of squares regression', Journal of the American Statistical Association 79(338), 871-881.

Rousseeuw, P. J. \& Van Driessen, K. (1999), 'A fast algorithm for the minimum covariance determinant estimator', Technometrics 41(3), 212-223.

Rubinstein, M. (1973), 'The fundamental theorem of parameter preference security valuation', The Journal of Financial and Quantitative Analysis 8(1), 6169.

Samuelson, P. A. (1970), 'The fundamental approximation of theorem of portfolio analysis in terms of means, variances and higher moments', The Review of Economic Studies 37(4), 537-542.

Triola, M. F. (2005), Introdução à estatística, 1 edn, LTC.

Tversky, A. \& Kahneman, D. (1991), 'Loss-aversion in riskless choice: a reference-dependent model', The Quarterly Journal of Economics 106(4), 1039-1061. 


\section{Apêndice A}

Tabela A.1: Relação e informações dos fundos de ações com gestão ativa selecionados

\begin{tabular}{|c|c|c|c|c|}
\hline Nome do fundo de investimento & $\mathrm{N}^{\circ}$ Fundo & Alavancado & $\begin{array}{l}\text { Taxa anual } \\
\text { de Adminis- } \\
\text { tração }\end{array}$ & $\begin{array}{l}\text { Taxa de } \\
\text { performance }\end{array}$ \\
\hline ALFA DINÂMICO FIC AÇÕES & 1 & Sim & 4,50 & Não cobra \\
\hline ALFA FIC AÇÕES & 2 & Sim & 8,50 & Não cobra \\
\hline ALFA SPECIAL FI ACÕES & 3 & Sim & 2,00 & Não cobra \\
\hline ALFAMAIS FIC AÇÕES & 4 & $\operatorname{Sim}$ & 7,50 & Não cobra \\
\hline ÁTICO AÇÕES FI AÇÕES & 5 & Não & 3,00 & Não cobra \\
\hline $\begin{array}{l}\text { BANCO DO NORDESTE } \\
\text { FI AÇÕES }\end{array}$ & 6 & Não & 3,00 & Não cobra \\
\hline BANRISUL ÍNDICE FI AÇÕES & 7 & Não & 4,00 & Não cobra \\
\hline $\begin{array}{l}\text { BB IBOVESPA ATIVO } \\
\text { FIC AÇÕES }\end{array}$ & 8 & Não & 3,00 & Não cobra \\
\hline BRADESCO BA FIC AÇÕES & 9 & Não & 4,00 & Não cobra \\
\hline BRADESCO FIC AÇÕES & 10 & Não & 4,00 & Não cobra \\
\hline $\begin{array}{l}\text { BRADESCO IBOVESPA } \\
\text { ATIVO FIC AÇÕES }\end{array}$ & 11 & Não & 4,00 & Não cobra \\
\hline BRADESCO IV FIC AÇÕES & 12 & Não & 4,00 & Não cobra \\
\hline BRADESCO MAXI FIC AÇÕES & 13 & Não & 4,00 & Não cobra \\
\hline $\begin{array}{l}\text { BRADESCO PRIME ACTIVE FIC } \\
\text { AÇÕES }\end{array}$ & 14 & Sim & 2,50 & Não cobra \\
\hline $\begin{array}{l}\text { BRADESCO PRIVATE } \\
\text { ALAVANCADO IBOVESPA } \\
\text { FI ACÕES }\end{array}$ & 15 & Sim & 2,00 & Não cobra \\
\hline $\begin{array}{l}\text { BRADESCO SUPER AÇÃO } \\
\text { FI AÇÕES }\end{array}$ & 16 & Não & 0,80 & Não cobra \\
\hline BRAM FIB FI AÇÕES & 17 & Não & 0,23 & 15,00 \\
\hline $\begin{array}{l}\text { BTG PACTUAL ANDRÔMEDA FI } \\
\text { AÇÕES }\end{array}$ & 18 & Não & 1,50 & 20,00 \\
\hline COINVALORES FI AÇÕES & 19 & Sim & 3,00 & Não cobra \\
\hline $\begin{array}{l}\text { COMERCIAL MASTER } \\
\text { FI AÇÕES }\end{array}$ & 20 & Sim & 2,50 & 20,00 \\
\hline ELITE FI AÇÕES & 21 & Não & 2,00 & Não cobra \\
\hline $\begin{array}{l}\text { FAMA CHALLENGER } \\
\text { FIC AÇÕES }\end{array}$ & 22 & Não & 2,00 & 20,00 \\
\hline $\begin{array}{l}\text { FATOR INSTITUCIONAL } \\
\text { FI AÇÕES }\end{array}$ & 23 & Não & 0,40 & 18,00 \\
\hline FATOR JAGUAR FI AÇÕES & 24 & Sim & 2,00 & 20,00 \\
\hline FIBRA VIC FI AÇÕES & 25 & Não & 2,50 & Não cobra \\
\hline HSBC FIC AÇÕES & 26 & Não & 2,50 & Não cobra \\
\hline ITAPOÃ FI AÇÕES & 27 & Não & 0,50 & Não cobra \\
\hline $\begin{array}{l}\text { ITAÚ CARTEIRA LIVRE } \\
\text { FI AÇÕES }\end{array}$ & 28 & Sim & 4,00 & Não cobra \\
\hline $\begin{array}{l}\text { ITAƯ INSTITUCIONAL } \\
\text { IBOVESPA ATIVO } \\
\text { FI AÇÕES }\end{array}$ & 29 & Não & 0,90 & Não cobra \\
\hline
\end{tabular}


Tabela A.1: Relação e informações dos fundos de ações com gestão ativa selecionados (continuação)

\begin{tabular}{|c|c|c|c|c|}
\hline Nome do fundo de investimento & No Fundo & Alavancado & $\begin{array}{l}\text { Taxa anual } \\
\text { de Adminis- } \\
\text { tração }\end{array}$ & $\begin{array}{l}\text { Taxa de } \\
\text { performance }\end{array}$ \\
\hline $\begin{array}{l}\text { ITAÚ PERSONNALITÉ } \\
\text { IBOVESPA ATIVO } \\
\text { FI AÇÕES }\end{array}$ & 30 & Sim & 2,00 & Não cobra \\
\hline $\begin{array}{l}\text { ITAÚ PRIVATE ATIVO } \\
\text { FI AÇÕES }\end{array}$ & 31 & Não & 2,00 & Não cobra \\
\hline $\begin{array}{l}\text { ITAÚ PRIVATE } \\
\text { EXPERTISE } \\
\text { FIC AÇÕES }\end{array}$ & 32 & Não & 0,00 & Não cobra \\
\hline $\begin{array}{l}\text { ITAÚ SELECT IBOVESPA } \\
\text { FIC AÇÕES }\end{array}$ & 33 & Sim & 4,00 & Não cobra \\
\hline $\begin{array}{l}\text { LEGG MASON PORTFÓLIO } \\
\text { FI AÇÕES }\end{array}$ & 34 & não & 0,00 & Não cobra \\
\hline $\begin{array}{l}\text { LEGG MASON PRIVATE } \\
\text { FOCUS FIC AÇÕES }\end{array}$ & 35 & Não & 4,00 & Não cobra \\
\hline $\begin{array}{l}\text { LEGG MASON SILVER } \\
\text { IBOVESPA ATIVO } \\
\text { FIC AÇÕES }\end{array}$ & 36 & Não & 4,00 & Não cobra \\
\hline LUXOR FI AÇÕES & 37 & Não & 0,10 & 30,00 \\
\hline MAGLIANO FI AÇÕES & 38 & Sim & 2,00 & 20,00 \\
\hline $\begin{array}{l}\text { MULTIPLY VARIABLE } \\
\text { FI AÇÕES }\end{array}$ & 39 & Não & 0,10 & 30,00 \\
\hline $\begin{array}{l}\text { OPPORTUNITY LÓGICA II FIC } \\
\text { AÇÕES }\end{array}$ & 40 & Sim & 0,00 & Não cobra \\
\hline PREVIDÊNCIA B FI AÇÕES & 41 & Não & 0,10 & 30,00 \\
\hline $\begin{array}{l}\text { PRÓSPERO ADINVEST } \\
\text { FI AÇÕES }\end{array}$ & 42 & Sim & 4,00 & Não cobra \\
\hline RT GALÁXIA FI AÇÕES & 43 & Não & 0,00 & Não cobra \\
\hline SAFRA AÇÕES FI AÇÕES & 44 & Não & 3,95 & Não cobra \\
\hline SAFRA PRIVATE FI AُÇÕES & 45 & Sim & 1,00 & Não cobra \\
\hline SANTANDER FI AÇÕES & 46 & Não & 4,00 & Não cobra \\
\hline $\begin{array}{l}\text { SANTANDER INSTITUCIONAL } \\
\text { BR IBOVESPA } \\
\text { FI AÇÕES }\end{array}$ & 47 & Não & 1,00 & Não cobra \\
\hline $\begin{array}{l}\text { SANTANDER ÔNIX } \\
\text { FIC AÇÕES I }\end{array}$ & 48 & Não & 2,50 & Não cobra \\
\hline $\begin{array}{l}\text { SANTANDER PLUS } \\
\text { FIC AÇÕES }\end{array}$ & 49 & Não & 5,00 & Não cobra \\
\hline SLW FI AÇÕES & 50 & Não & 4,00 & Não cobra \\
\hline $\begin{array}{l}\text { SUL AMÉRICA } \\
\text { EQUILIBRIUM FI AÇÕES }\end{array}$ & 51 & Sim & 3,00 & Não cobra \\
\hline UNIBANCO BLUE FI AÇÕES & 52 & Não & 5,00 & Não cobra \\
\hline $\begin{array}{l}\text { UNIBANCO PREVIDÊNCIA IBO- } \\
\text { VESPA FI AÇÕES }\end{array}$ & 53 & Não & 0,00 & Não cobra \\
\hline $\begin{array}{l}\text { UNIBANCO STRATEGY } \\
\text { FI AÇÕES }\end{array}$ & 54 & Sim & 3,00 & Não cobra \\
\hline $\begin{array}{l}\text { UNIBANCO TIMING } \\
\text { FI AÇÕES }\end{array}$ & 55 & Sim & 2,50 & 20,00 \\
\hline VOTORANTIM FI AÇÕES & 56 & Não & 1,80 & 20,00 \\
\hline
\end{tabular}


Tabela A.2: Percentual de janelas em que o desviopadrão dos fundos de ações com gestão ativa selecionados foi maior do que o desvio-padrão da carteira de mínima variância global (MVP) com pesos limitados a dez por cento para janelas móveis de 1 , $21,42,63,126,252$ e 504 dias úteis

\begin{tabular}{|c|c|c|c|c|c|c|c|}
\hline Fundo & 1 & 21 & 42 & 63 & 126 & 252 & 504 \\
\hline 1 & 48,51 & 44,53 & 43,74 & 43,59 & 40,63 & 34,53 & 27,34 \\
\hline 2 & 48,16 & 42,58 & 38,39 & 35,96 & 30,82 & 25,88 & 12,20 \\
\hline 3 & 49,00 & 45,94 & 45,27 & 45,80 & 43,01 & 37,71 & 31,21 \\
\hline 4 & 48,54 & 44,34 & 43,47 & 42,74 & 40,79 & 34,41 & 26,26 \\
\hline 5 & 50,09 & 45,86 & 45,89 & 45,52 & 45,91 & 37,88 & 32,66 \\
\hline 6 & 49,87 & 46,17 & 43,97 & 43,90 & 39,16 & 37,42 & 31,87 \\
\hline 7 & 49,91 & 48,00 & 45,39 & 44,87 & 41,66 & 46,32 & 34,81 \\
\hline 8 & 49,34 & 44,45 & 42,47 & 40,68 & 36,38 & 31,23 & 21,87 \\
\hline 9 & 49,91 & 46,51 & 43,50 & 41,46 & 42,65 & 42,22 & 27,85 \\
\hline 10 & 49,22 & 46,47 & 44,31 & 42,46 & 39,95 & 38,04 & 28,79 \\
\hline 11 & 50,17 & 49,18 & 46,93 & 47,46 & 44,88 & 45,94 & 36,12 \\
\hline 12 & 49,26 & 42,24 & 39,82 & 35,99 & 34,35 & 33,65 & 18,97 \\
\hline 13 & 49,07 & 42,28 & 39,85 & 36,54 & 34,67 & 28,68 & 18,97 \\
\hline 14 & 51,12 & 51,24 & 49,96 & 51,96 & 53,10 & 53,64 & 46,82 \\
\hline 15 & 49,87 & 50,29 & 50,15 & 49,67 & 51,91 & 53,80 & 49,67 \\
\hline 16 & 49,26 & 43,42 & 42,24 & 41,61 & 38,76 & 37,00 & 31,12 \\
\hline 17 & 50,55 & 48,65 & 48,58 & 48,04 & 47,50 & 49,58 & 43,88 \\
\hline 18 & 50,36 & 52,61 & 54,15 & 51,76 & 53,18 & 58,32 & 48,97 \\
\hline 19 & 50,89 & 46,85 & 45,35 & 45,41 & 45,04 & 39,67 & 44,58 \\
\hline 20 & 51,19 & 53,11 & 55,80 & 55,99 & 60,88 & 55,02 & 58,22 \\
\hline 21 & 49,91 & 52,38 & 52,88 & 54,17 & 53,49 & 52,01 & 52,94 \\
\hline 22 & 50,66 & 51,58 & 52,19 & 53,20 & 53,53 & 58,03 & 67,06 \\
\hline 23 & 50,09 & 47,05 & 44,50 & 45,45 & 44,36 & 42,98 & 32,66 \\
\hline 24 & 50,25 & 49,90 & 49,54 & 51,22 & 52,07 & 45,90 & 55,84 \\
\hline 25 & 50,70 & 49,87 & 50,81 & 50,68 & 50,83 & 57,11 & 49,63 \\
\hline 26 & 49,30 & 46,32 & 41,97 & 40,10 & 37,13 & 33,95 & 29,16 \\
\hline 27 & 48,77 & 45,75 & 42,97 & 42,19 & 38,17 & 36,33 & 28,32 \\
\hline 28 & 49,56 & 47,62 & 45,04 & 46,34 & 45,59 & 46,49 & 39,49 \\
\hline 29 & 49,68 & 48,11 & 46,73 & 48,59 & 47,62 & 51,13 & 41,54 \\
\hline 30 & 50,13 & 48,34 & 46,73 & 46,73 & 44,84 & 49,83 & 42,76 \\
\hline 31 & 49,94 & 49,33 & 48,39 & 49,48 & 47,90 & 52,59 & 43,22 \\
\hline 32 & 50,66 & 49,83 & 47,81 & 47,97 & 46,66 & 47,70 & 47,29 \\
\hline 33 & 49,64 & 48,11 & 47,43 & 48,00 & 48,09 & 52,05 & 42,52 \\
\hline 34 & 50,36 & 48,91 & 47,00 & 47,54 & 46,78 & 53,68 & 40,61 \\
\hline 35 & 50,36 & 48,72 & 46,77 & 47,31 & 46,58 & 53,55 & 40,61 \\
\hline 36 & 50,13 & 47,31 & 44,47 & 45,52 & 43,53 & 47,87 & 37,48 \\
\hline 37 & 50,02 & 48,30 & 48,96 & 49,13 & 46,98 & 49,92 & 40,23 \\
\hline 38 & 48,39 & 45,90 & 45,85 & 43,70 & 40,98 & 31,81 & 23,88 \\
\hline 39 & 50,47 & 48,27 & 49,46 & 49,28 & 42,85 & 49,92 & 41,40 \\
\hline 40 & 51,27 & 51,73 & 51,42 & 51,07 & 56,95 & 61,91 & 66,45 \\
\hline 41 & 50,06 & 46,59 & 45,96 & 46,49 & 43,45 & 47,32 & 37,80 \\
\hline 42 & 51,34 & 54,06 & 57,57 & 61,18 & 65,89 & 72,12 & 79,21 \\
\hline 43 & 50,32 & 51,77 & 53,69 & 52,69 & 52,34 & 57,65 & 53,27 \\
\hline 44 & 49,56 & 48,80 & 47,23 & 47,77 & 46,35 & 48,91 & 43,27 \\
\hline 45 & 49,64 & 47,73 & 45,77 & 45,68 & 48,69 & 51,51 & 39,63 \\
\hline 46 & 50,09 & 46,89 & 45,73 & 47,31 & 43,92 & 48,12 & 38,04 \\
\hline 47 & 50,47 & 49,87 & 50,31 & 50,29 & 49,29 & 50,17 & 41,73 \\
\hline 48 & 49,45 & 42,89 & 39,24 & 38,05 & 32,96 & 25,21 & 16,87 \\
\hline 49 & 50,32 & 48,72 & 48,89 & 49,05 & 47,74 & 48,54 & 38,46 \\
\hline 50 & 48,96 & 44,22 & 42,97 & 43,39 & 43,57 & 44,31 & 35,33 \\
\hline 51 & 50,59 & 50,86 & 51,11 & 50,41 & 51,19 & 49,83 & 47,80 \\
\hline 52 & 49,87 & 46,17 & 44,93 & 44,05 & 40,67 & 39,38 & 33,18 \\
\hline 53 & 49,53 & 44,34 & 42,28 & 41,38 & 40,31 & 36,08 & 32,57 \\
\hline 54 & 50,09 & 47,16 & 44,77 & 44,98 & 42,61 & 45,23 & 34,02 \\
\hline 55 & 52,63 & 47,69 & 46,43 & 44,91 & 40,63 & 42,68 & 37,43 \\
\hline 56 & 48,81 & 46,78 & 45,70 & 45,56 & 46,78 & 45,90 & 42,52 \\
\hline Amostras & 2643 & 2623 & 2602 & 2581 & 2518 & 2392 & 2140 \\
\hline
\end{tabular}


Tabela A.3: Percentual de janelas em que o desvio-padrão dos fundos de ações com gestão ativa selecionados foi maior do que o desviopadrão da carteira de mínima variância global (MVP) com pesos limitados a dez por cento para janelas móveis de $1,21,42,63,126,252$ e 504 dias úteis

\begin{tabular}{|c|c|c|c|c|c|c|}
\hline Fundo & 21 & 42 & 63 & 126 & 252 & 504 \\
\hline 1 & 24,97 & 22,33 & 16,54 & 8,54 & 3,55 & 0,00 \\
\hline 2 & 36,07 & 33,01 & 30,72 & 23,99 & 20,53 & 8,74 \\
\hline 3 & 22,68 & 18,60 & 13,95 & 6,75 & 1,46 & 0,00 \\
\hline 4 & 24,93 & 21,98 & 16,35 & 8,26 & 3,22 & 0,00 \\
\hline 5 & 40,34 & 40,35 & 39,29 & 40,19 & 42,14 & 36,96 \\
\hline 6 & 28,56 & 21,83 & 18,09 & 12,31 & 0,71 & 0,00 \\
\hline 7 & 23,79 & 21,21 & 20,07 & 13,03 & 11,96 & 0,00 \\
\hline 8 & 22,84 & 19,06 & 15,73 & 8,22 & 4,10 & 0,00 \\
\hline 9 & 44,91 & 43,08 & 38,32 & 31,65 & 27,76 & 12,99 \\
\hline 10 & 34,46 & 32,71 & 27,59 & 18,03 & 13,38 & 2,94 \\
\hline 11 & 25,24 & 21,68 & 18,36 & 12,11 & 9,36 & 0,00 \\
\hline 12 & 26,42 & 25,21 & 20,53 & 13,74 & 12,17 & 2,38 \\
\hline 13 & 28,97 & 25,90 & 20,69 & 13,26 & 12,17 & 2,34 \\
\hline 14 & 24,17 & 18,72 & 16,35 & 11,28 & 5,56 & 0,00 \\
\hline 15 & 24,40 & 21,21 & 18,91 & 11,48 & 6,77 & 0,00 \\
\hline 16 & 25,31 & 22,37 & 20,38 & 17,04 & 11,87 & 5,61 \\
\hline 17 & 33,93 & 30,13 & 26,77 & 29,51 & 26,17 & 20,19 \\
\hline 18 & 22,87 & 16,22 & 12,98 & 7,07 & 0,33 & 0,00 \\
\hline 19 & 32,33 & 27,71 & 24,45 & 20,53 & 14,34 & 9,72 \\
\hline 20 & 30,39 & 26,13 & 25,57 & 22,52 & 22,78 & 22,52 \\
\hline 21 & 57,34 & 55,57 & 57,11 & 61,87 & 75,13 & 81,87 \\
\hline 22 & 58,18 & 58,03 & 57,15 & 58,50 & 55,81 & 58,97 \\
\hline 23 & 35,38 & 32,36 & 30,30 & 25,89 & 23,04 & 25,65 \\
\hline 24 & 34,01 & 30,90 & 28,59 & 21,33 & 15,97 & 7,43 \\
\hline 25 & 37,93 & 36,05 & 33,32 & 23,91 & 14,92 & 10,05 \\
\hline 26 & 25,81 & 20,52 & 17,47 & 9,25 & 4,06 & 0,00 \\
\hline 27 & 31,45 & 28,13 & 23,17 & 13,58 & 4,68 & 0,00 \\
\hline 28 & 21,81 & 19,68 & 15,81 & 10,92 & 8,78 & 0,00 \\
\hline 29 & 22,00 & 16,10 & 13,17 & 8,30 & 1,63 & 0,00 \\
\hline 30 & 23,14 & 21,25 & 16,85 & 11,28 & 9,07 & 0,00 \\
\hline 31 & 24,86 & 21,60 & 17,71 & 12,27 & 8,65 & 0,00 \\
\hline 32 & 0,04 & 0,00 & 0,00 & 0,00 & 0,00 & 0,00 \\
\hline 33 & 21,88 & 17,18 & 13,44 & 4,09 & 1,55 & 0,00 \\
\hline 34 & 24,78 & 19,75 & 16,20 & 8,70 & 4,35 & 0,00 \\
\hline 35 & 24,78 & 19,75 & 16,16 & 8,66 & 4,31 & 0,00 \\
\hline 36 & 24,74 & 19,68 & 16,16 & 8,66 & 4,31 & 0,00 \\
\hline 37 & 42,62 & 40,39 & 36,85 & 40,15 & 37,50 & 28,27 \\
\hline 38 & 32,75 & 27,94 & 25,11 & 22,32 & 25,63 & 19,67 \\
\hline 39 & 40,11 & 37,13 & 33,86 & 32,72 & 29,47 & 25,42 \\
\hline 40 & 24,70 & 19,37 & 16,66 & 8,86 & 3,60 & 0,00 \\
\hline 41 & 43,12 & 41,89 & 40,10 & 37,85 & 38,50 & 30,42 \\
\hline 42 & 54,90 & 55,19 & 56,57 & 59,09 & 64,01 & 78,22 \\
\hline 43 & 53,76 & 52,69 & 51,96 & 47,82 & 39,46 & 43,74 \\
\hline 44 & 35,99 & 32,28 & 28,52 & 29,63 & 35,74 & 35,28 \\
\hline 45 & 30,04 & 27,25 & 24,22 & 20,41 & 17,18 & 25,14 \\
\hline 46 & 22,46 & 16,64 & 12,86 & 8,26 & 1,63 & 0,00 \\
\hline 47 & 24,29 & 19,83 & 16,78 & 10,52 & 5,64 & 0,00 \\
\hline 48 & 22,95 & 17,26 & 14,45 & 8,26 & 1,84 & 0,00 \\
\hline 49 & 22,68 & 19,22 & 16,39 & 10,05 & 5,31 & 0,00 \\
\hline 50 & 47,92 & 48,50 & 47,73 & 45,27 & 45,32 & 24,07 \\
\hline 51 & 38,54 & 38,47 & 38,24 & 35,46 & 28,60 & 32,71 \\
\hline 52 & 29,28 & 25,44 & 20,38 & 11,24 & 7,23 & 0,00 \\
\hline 53 & 29,51 & 27,63 & 22,94 & 13,66 & 5,94 & 0,00 \\
\hline 54 & 21,88 & 18,52 & 12,59 & 6,12 & 1,05 & 0,00 \\
\hline 55 & 34,20 & 30,09 & 27,24 & 21,01 & 15,01 & 19,39 \\
\hline 56 & 21,65 & 16,72 & 12,32 & 6,24 & 0,00 & 0,00 \\
\hline Amostras & 2623 & 2602 & 2581 & 2518 & 2392 & 2140 \\
\hline
\end{tabular}

